\title{
Surface Modification of Nanoclays with Styrene-Maleic Anhydride Copolymers
}

\author{
Refik Arat ${ }^{1,2}$, Nurseli Uyanık ${ }^{2}$ \\ ${ }^{1}$ Department of Civil Engineering, Istanbul Kultur University, Istanbul, Turkey \\ ${ }^{2}$ Chemistry Department, Arts and Science Faculty, Istanbul Technical University, Istanbul, Turkey \\ Email:r.arat@iku.edu.tr, uyanik@itu.edu.tr
}

How to cite this paper: Arat, R. and Uyanık, N. (2017) Surface Modification of Nanoclays with Styrene-Maleic Anhydride Co- polymers. Natural Resources, 8, 159171.

https://doi.org/10.4236/nr.2017.83011

Received: February 11, 2017

Accepted: March 28, 2017

Published: March 31, 2017

Copyright ( $\odot 2017$ by authors and Scientific Research Publishing Inc. This work is licensed under the Creative Commons Attribution International License (CC BY 4.0).

http://creativecommons.org/licenses/by/4.0/

(c) (i) Open Access

\begin{abstract}
This study presents the modification of surfaces of nanoclays, halloysite nanotubes (HNT) and sepiolite (SEP), with styrene-maleic anhydride copolymers (SMA) via esterification reaction between hydroxyl groups of the nanoclays and anhydride groups of SMA. The structural, thermal, and morphological analyses of the modified nanoclays were performed by Fourier transform infrared spectroscopy (FTIR), X-ray diffraction analysis (XRD), thermal gravimetric analysis (TGA), and field emission scanning electron microscopy (FESEM). All of these results suggested that the expected modification of HNT and SEP surfaces were performed. Although XRD patterns of HNT containing samples showed that the basal spacing shifted to higher distances, it was found that those of the crystalline structure of SEP remained unchanged. Thermal gravimetric analysis exhibited that SMA copolymers were grafted onto the surfaces of nanoclays varying amounts between 15 and 43 wt. \% depending on the types of nanoclays and SMA copolymers. This modification indicates that these nanoclays can be added to the polystyrene matrix without any compatibilizers.
\end{abstract}

\section{Keywords}

Halloysite Nanotubes, Sepiolite, Styrene-Maleic Anhydride Copolymer, Surface Modification of Nanoclays

\section{Introduction}

Nanoclays have been employed as fillers in polymers to improve their mechanical performance, thermal stability, barrier properties and flame retardancy [1]-[6]. Various kinds of nanoclays such as montmorillonite [7] [8], kaolinite [9] [10], hectorite [11] [12], saponite [13] [14] have attracted the great attention of scientists and technologists within both academia and industrial area. 
Halloysite nanotubes (HNT), due to its hollow tubular structure, large aspect ratio, natural availability, rich functionality, good biocompatibility, and high mechanical strength, has been used in the production of polymer/clay nanocomposites in recent years [15]. HNT consists of aluminosilicate nanotubes similar to the structure of kaolinite and has a molecular formula of $\mathrm{Al}_{2} \mathrm{Si}_{2} \mathrm{O}_{5}(\mathrm{OH})_{4} \cdot \mathrm{nH}_{2} \mathrm{O}$. The internal diameter of the hollow nanotubes is in the range of $10-70 \mathrm{~nm}$, and the length of the nanotubes is varying from 0.2 to 1.5 $\mu \mathrm{m}$ [16]. HNT's body consists of two different interlayer surfaces, which are the internal surface containing aluminol $(\mathrm{Al}-\mathrm{OH})$ groups and the external surface covered by siloxane (Si-O-Si) groups. Further, some silanol (Si-OH) and aluminol groups exist at the edges of the tubes [17] [18] [19]. These hydroxyl groups caused polarity on the HNT surface offer an opportunity to obtain efficient dispersion of HNT into the polar polymeric matrices [20] [21]. Sepiolite (SEP), a natural hydrated magnesium silicate with the theoretical formula of

$\mathrm{Si}_{12} \mathrm{Mg}_{8} \mathrm{O}_{30}(\mathrm{OH})_{4}\left(\mathrm{OH}_{2}\right)_{4} \cdot 8 \mathrm{H}_{2} \mathrm{O}$, is used as a reinforcing nanofiller in various polymer matrices [22] [23] [24]. The discontinuity of the silica sheets in sepiolite leads to the characteristic structural tunnels, which possess silanol groups (Si-OH) at their edges. [25] [26]. In the polar polymeric matrix, these silanolgroups not only improve the interactions between SEP and the host polymer, but also enhance the dispersion of SEP without any kind of modification [27] [28] [29] [30].

The surface modifications of inorganic nanoclays with organic compounds are widely applied to improve the dispersion and compatibility of the polymer/ nanoclay composites. Joo et al. (2012) modified the functional groups of HNT from hydroxyl groups (HNT-OH) to carboxylic acids (HNT-COOH) to show only the ability of these hydroxyl groups [31]. Du et al. (2006) modified HNT surface via chemically grafting polypropylene (PP) with a two-step method and investigated the compatibility of modified HNT into PP matrix. In the first step, HNT surface was functionalized with $\gamma$-aminopropyltriethoxysilane and then PP chains were grafted onto the surface of HNT via commercialized maleic anhydride grafted PP (PP-g-MAH). They found that the modified HNT showed much lower polarity compared to pristine HNT and increased the mechanical properties compared with neat PP and PP/pristine HNT nanocomposites [32]. Pasbakhsh et al. (2010) modified the surface of HNT by $\gamma$-methacryloxypropyltrimethoxysilane to improve their dispersion in ethylene propylene diene monomer [19]. Garcia et al. (2011) modified SEP surface with trimethoxysilane via chemically in aqueous gel procedures to improve its compatibility in PP, LDPE and PS matrices [33]. Garcia-Lopez et al. (2010) modified SEP surface with trimethyl hydrogenated tallow quaternary ammonium (3MTH) and PA6/organomodified SEP nanocomposites were obtained by using different amounts of modified SEP. They observed that the nanocomposites with the highest amount of modifier displayed the best mechanical properties [34]. Di et al. (2004) also studied grafting reaction of methyltriethoxysilane on SEP surfaces to investigate the reactivity of silanol groups [35]. 
In this paper, we studied the surface modification of HNT and SEP with the two different commercial styrene-maleic anhydride copolymers (SMA), which have different molecular weight and styrene/maleic anhydride molar ratio, through esterification reaction in THF medium. The modified nanoclays were characterized by Fourier transform infrared spectroscopy (FTIR), X-ray diffraction analysis (XRD), thermal gravimetric analysis (TGA), and field emission scanning electron microscopy (FESEM).

\section{Experimental Part}

\subsection{Materials}

A commercial grade of HNT was provided by ESAN Eczacibasi (Turkey). The elemental composition of $\mathrm{HNT}$ is as follows (wt. \%): $\mathrm{SiO}_{2}, 43.30 ; \mathrm{Al}_{2} \mathrm{O}_{3}, 38.40$; $\mathrm{Fe}_{2} \mathrm{O}_{3}, 0.80 ; \mathrm{TiO}_{2}, 0.10$. SEP powder was purchased from Sigma-Aldrich (Germany). The commercial styrene-maleic anhydride copolymers (SMA), namely SMA- $1000^{\circ}$ and SMA-EF $40^{\circ}$ flake, were provided by Cray Valley (USA). Table 1 gives the details of the SMA. Tetrahydrofuran (THF) and $p$-toluene sulfonic acid (PTSA) were obtained from Sigma-Aldrich (Germany). All the materials were employed without further purification.

\subsection{Modification of Nanoclays}

Modification of the nanoclays was prepared through the esterification reaction by using PTSA as the catalyst in THF medium. The modification reaction is detailed in Figure 1.

\subsection{Characterization of the Modified Nanoclays}

The FTIR measurements were carried out by Perkin Elmer Spectrum 100 FTIR spectrometer in attenuated total reflection (ATR) accessory. Infrared spectra were collected between $4000-650 \mathrm{~cm}^{-1}$ at a resolution of $4 \mathrm{~cm}^{-1}$.

The X-ray diffraction (XRD) patterns were recorded using the Shimadzu LabX XRD-6100 diffractometer. The $\mathrm{Cu} \mathrm{K} \alpha(\lambda=1.54060 \AA)$ was operated at 40 $\mathrm{kV}$ and $40 \mathrm{~mA}$. The samples were scanned from $2 \theta=0^{\circ}-40^{\circ}$.

The TG analysis (TGA) was performed using a SEIKO Exstar 6200 TG/DTA instrument. The samples were heated from room temperature to $700^{\circ} \mathrm{C}$ with a heating rate of $10^{\circ} \mathrm{C} / \mathrm{min}$ under nitrogen atmosphere with a purging rate of 150 $\mathrm{mL} / \mathrm{min}$.

The nanoclays samples for field emission scanning electron microscopy (FESEM) were prepared by coating with a thin conductive layer of gold onto the

Table 1. The trade names, molecular weight and molar ratio of styrene/maleic anhydride of SMA.

\begin{tabular}{ccc}
\hline Trade name & Molecular weight $(\mathrm{g} / \mathrm{mole})$ & Molar ratio of styrene/maleic anhydride \\
\hline SMA-1000 & 5500 & $1 / 1$ \\
SMA-EF40 & 10,000 & $4 / 1$ \\
\hline
\end{tabular}


$5 \mathrm{~g}$ of SMA is dissolved in $100 \mathrm{~mL}$ of THF

$5 \mathrm{~g}$ of nanoclay (HNT or SEP) is added to the SMA solution (weight ratio of SMA:Nanoclay is 1:1)

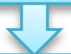

The solution is stirred at $1000 \mathrm{rpm}$ for $15 \mathrm{~min}$ at $70^{\circ} \mathrm{C}$ on a hotplate with a magnetic stirrer under nitrogen atmosphere

$0.04 \mathrm{~g}$ of PTSA (4wt. \% of total amount of reactants) is added to the solution

The solution is refluxed at $70^{\circ} \mathrm{C}$ for 24 hours under nitrogen atmosphere

The solution is filtered and the modified nanoclay is washed with THF by centrifuge for $10 \mathrm{~min}$ at $10000 \mathrm{rpm}$ (three times)

The modified nanoclay is dried at $60^{\circ} \mathrm{C}$ for 24 hours

Figure 1. The modification reaction scheme of the nanoclays with SMA copolymers.

samples. FESEM images of the samples were performed under high vacuum with FEI Quanta FEG 450 at $30 \mathrm{kV}$.

\section{Results and Discussion}

\subsection{Structural Analysis of the Modified Nanoclays}

FTIR spectra of the pristine HNT and modified HNT with SMA-1000 and SMA-EF40 (represented by HNT-1000 and HNT-EF40, respectively) are presented in Figure 2. The characteristic absorption peaks of the pristine HNT, such as the O-H stretching of inner hydroxyl groups at $3625 \mathrm{~cm}^{-1}$, O-H deformation of water at $1631 \mathrm{~cm}^{-1}$, O-H bending of inner hydroxyl groups at $906 \mathrm{~cm}^{-1}$ and Si-O stretching at $1004 \mathrm{~cm}^{-1}$ [18] [19] can be seen. The new vibration bands are observed in the FTIR spectra of HNT-1000 and HNT-EF40. The new bands at 1852 and $1776 \mathrm{~cm}^{-1}$ are assigned to the $\mathrm{C}=\mathrm{O}$ stretching vibration. Further, the FTIR bands at $3028-2919 \mathrm{~cm}^{-1}$ and $1495-1455 \mathrm{~cm}^{-1}$ are assigned to $=\mathrm{C}-\mathrm{H}$ and $\mathrm{C}=\mathrm{C}$ stretching of aromatic benzene ring, respectively. The FTIR spectrum of HNT-1000 displays some new absorption bands at 1707 and $1218 \mathrm{~cm}^{-1}$, which can be attributed to the formation of ester bonding between anhydride and - $\mathrm{OH}$ groups [36] [37]. The ester bonding formation exhibits that SMA-1000 copolymer is more efficiently grafted to HNT surface than SMA-EF40 due to its higher 


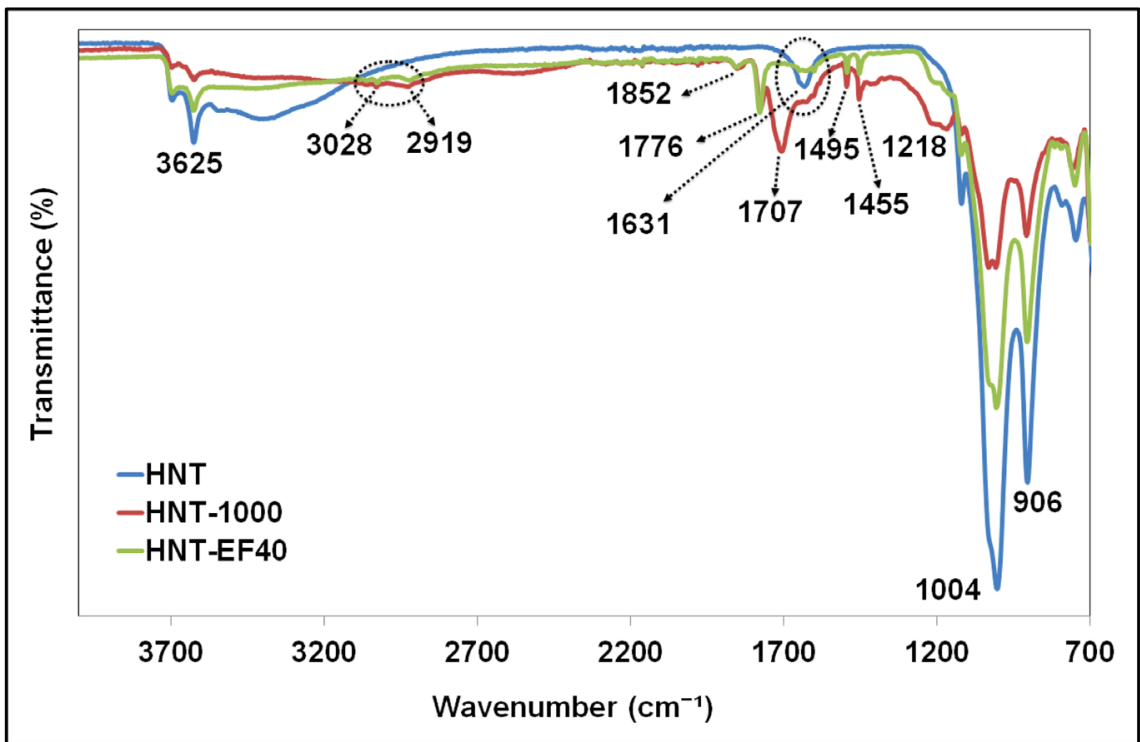

Figure 2. FTIR spectra of the pristine HNT, HNT-1000 and HNT-EF40.

maleic anhydride content and lower molecular weight.

Figure 3 gives the details of FTIR spectra of the pristine SEP and modified SEP samples which are modified with SMA-1000 (SEP-1000) and modified with SMA-EF40 (SEP-EF40). The bands at 3655 and $3564 \mathrm{~cm}^{-1}$ are assigned to the $\mathrm{Mg}-\mathrm{OH}$ groups [38], the broad band at 3404 and the peak at $1464 \mathrm{~cm}^{-1}$ show $\mathrm{O}-\mathrm{H}$ band stretching vibrations of zeolitic water, the peak at $1648 \mathrm{~cm}^{-1}$ is due to the stretching vibration of coordinated bonded water in SEP [35]. The band appeared at 1209 and $975 \mathrm{~cm}^{-1}$ are associated with Si-O bending and Si-O-Si stretching vibration, respectively [39].

Some new peaks are observed in the spectra of SEP-1000 and SEP-EF40, as well as modified HNT samples' FTIR spectra. The weak bands at 3028 and 2919 $\mathrm{cm}^{-1}$ are assigned to $=\mathrm{C}-\mathrm{H}$ stretching vibrations. The peaks at 1853 and 1776 $\mathrm{cm}^{-1}$ are attributed to the $\mathrm{C}=\mathrm{O}$ stretching vibration, the bands at 1493 and 1453 $\mathrm{cm}^{-1}$ are ascribed to $\mathrm{C}=\mathrm{C}$ stretching of aromatic benzene ring. Moreover, the wideness of the peak at $1706 \mathrm{~cm}^{-1}$ and $1656 \mathrm{~cm}^{-1}$ is owing to overlapping of the carbonyl $(\mathrm{C}=\mathrm{O})$ stretching vibration with the coordinated bonded water [25]. These new bands show that the kinds of SMA are chemically grafted onto the surface of SEP. As can be seen, SMA-1000 copolymer, possessing higher maleic anhydride content and lower molecular weight than SMA-EF40, is also efficiently grafted to SEP surface, as well as grafted to HNT.

Figure 4(a) exhibits XRD patterns of pristine and modified HNT-1000 samples. The characteristic $\mathrm{d}_{001}$ diffraction peak of pure HNT is located at $2 \theta=12.0^{\circ}$, corresponding to a basal spacing of $7.57 \AA$ Á. After the modification, the diffraction peak of HNT remains unchanged, which indicates that the tubular structure of HNT remained stable [17]. However, the modification causes a displacement of the $\mathrm{d}_{001}$ diffraction peak of HNT-1000 to lower angles with increasing in the basal spacing from 7.57 to $9.84 \AA$ Á. These results confirm that the interlayer distance of HNT increases with modification. 


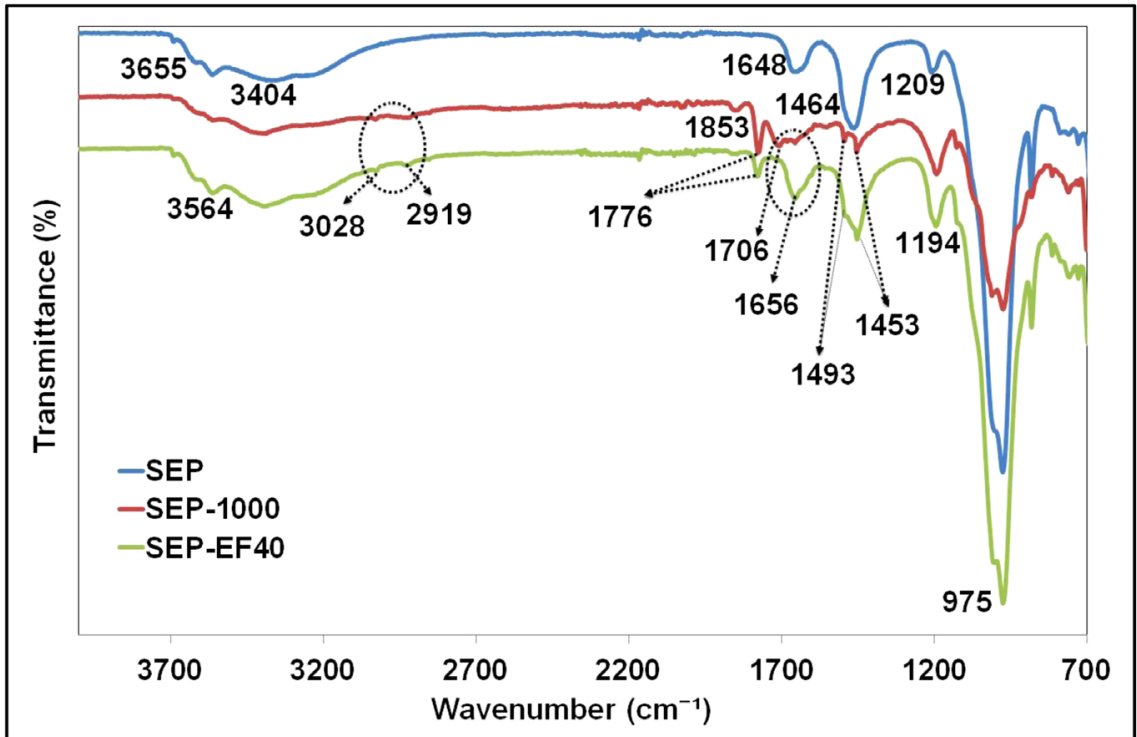

Figure 3. FTIR spectra of the pristine SEP, SEP-1000 and SEP-EF40.

The XRD patterns of the pristine SEP and modified SEP-1000 are given in Figure $4(\mathrm{~b})$. The characteristic $\mathrm{d}_{110}$ diffraction peak of SEP at $2 \theta$ value of $7.4^{\circ}$ corresponds to a basal spacing of $12.22 \AA$ A. The other characteristic peaks of pure SEP are at $2 \theta=19.70^{\circ}, 24.55^{\circ}, 27.25^{\circ}, 28.60^{\circ}, 30.45^{\circ}$ and $35.15^{\circ}$, which are, respectively, corresponded to basal spacing of $4.50 \AA$ Á, 3.71 Á, 3.32 Á, 3.18 Á, 2.88 Å and 2.57 Å. Owing to SEP layers linked each other via covalent bonding, changing the interlayer spacing of the SEP is extremely hard. Therefore, this modification does not affect the original SEP structure of the samples [40].

\subsection{Thermal Analysis of the Modified Nanoclays}

Figure 5 displays the weight loss (TGA) curves of the pristine HNT, the modified HNT samples and the commercial SMA copolymers. The pristine HNT exhibits two thermal decompositions in its TGA curve. The first weight loss started at the temperature of $30^{\circ} \mathrm{C}$ and ended at $80^{\circ} \mathrm{C}$ can be attributed to the loss of physically adsorbed water from the surface and internal channels of the tubes [41] [42]. The second weight loss occurs at the temperatures between $430^{\circ} \mathrm{C}$ $500^{\circ} \mathrm{C}$. This weight loss is assigned to dehydroxylation of the structural of the $\mathrm{Al}-\mathrm{OH}$ [18] and Si-OH [43] groups of HNT. The char residue of the pristine HNT is 74 wt. $\%$ at $700^{\circ} \mathrm{C}$.

The commercial SMA-1000 and SMA-EF40 show one-step thermal degradation process in the temperatures between $280^{\circ} \mathrm{C}-450^{\circ} \mathrm{C}$ and $320^{\circ} \mathrm{C}-430^{\circ} \mathrm{C}$, respectively. The char residues of SMA-1000 and SMA-EF40 are 6 and 0 wt. \% at $700^{\circ} \mathrm{C}$, respectively.

For the modified HNT samples, HNT-1000 and HNT-EF40, the first weight losses which come from the adsorbed water molecules at their surfaces are occurred between the temperatures of $30^{\circ} \mathrm{C}-200^{\circ} \mathrm{C}$ and $30^{\circ} \mathrm{C}-120^{\circ} \mathrm{C}$, respectively. Compared to the pristine HNT, the modified HNT samples show a reducing 


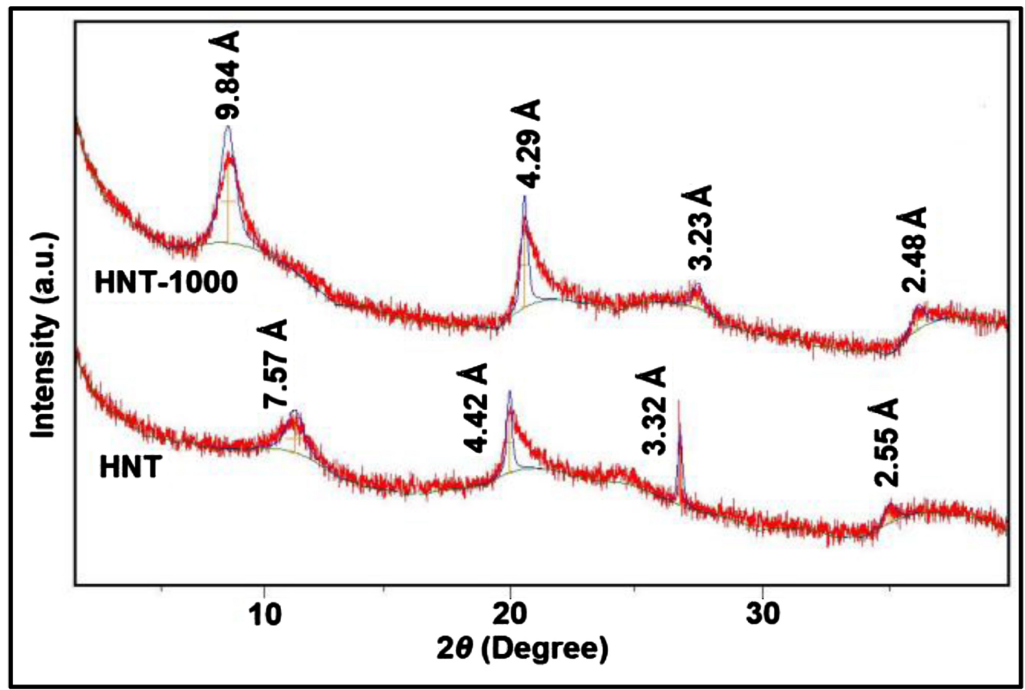

(a)

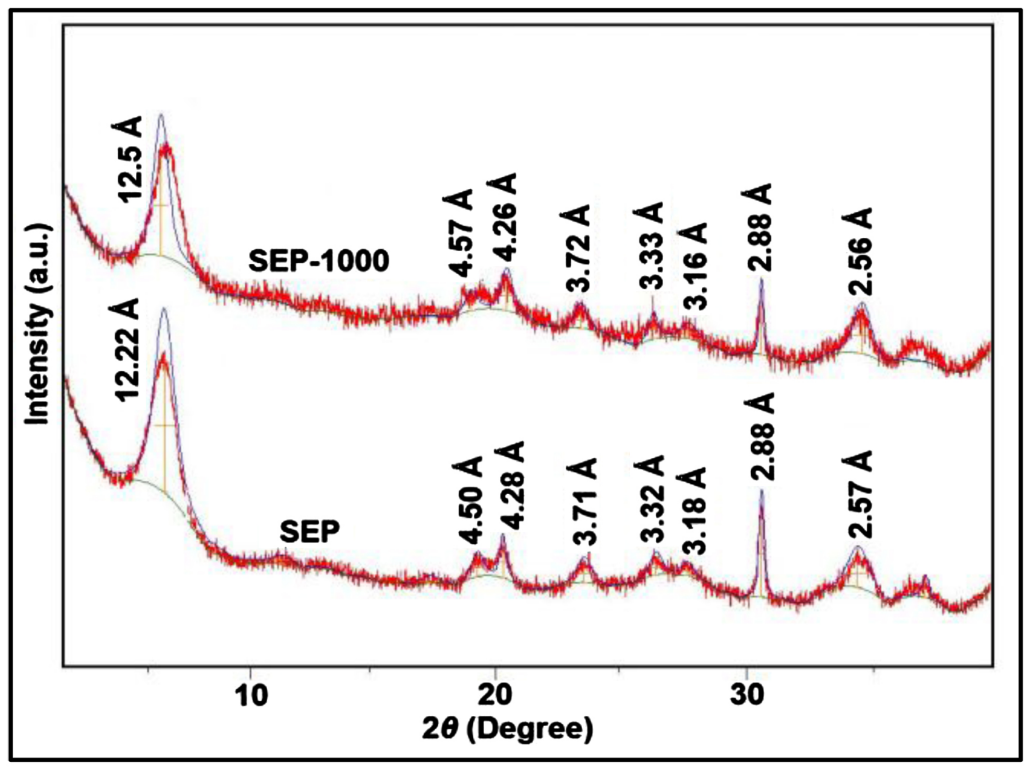

(b)

Figure 4. XRD patterns of (a) Pristine HNT and HNT-1000; (b) Pristine SEP and SEP-1000.

of the amount of adsorbed water molecules on the modified surfaces, which indicates an increment of the organic parts on their surfaces. The second weight loss between the temperatures of $320^{\circ} \mathrm{C}-500^{\circ} \mathrm{C}$ for HNT-1000 and $320^{\circ} \mathrm{C}$ $550^{\circ} \mathrm{C}$ for HNT-EF40 can be related to the degradation of organic molecules grafted on the HNT surfaces. The char residues of HNT-1000 and HNT-EF40 are 45 and 63 wt. $\%$ at $700^{\circ} \mathrm{C}$, respectively. These residue values indicate that 40 wt. \% of SMA-1000 and 16 wt. \% of SMA-EF40 grafted on the HNT surfaces. These results confirm that HNT surface is efficiently modified with SMA-1000 copolymer as demonstrated by FTIR and XRD analysis.

Thermal analysis was performed up to $900^{\circ} \mathrm{C}$ for the samples based on SEP. 
As can be seen from Figure 6, the pure SEP decomposes with four-step weight loss, where the first step is attributed to the removal of surface-adsorbed water at the temperature between $30^{\circ} \mathrm{C}-90^{\circ} \mathrm{C}$, the second step at the range of $230^{\circ} \mathrm{C}$ $300^{\circ} \mathrm{C}$ corresponds to the degradation of zeolitic water. The other steps occurred at the temperatures between $600^{\circ} \mathrm{C}-670^{\circ} \mathrm{C}$ and $770^{\circ} \mathrm{C}-820^{\circ} \mathrm{C}$ are related to the decomposition of coordinated water and hydroxyl groups, respectively [44]. The char residue of SEP is 76 wt. $\%$ at $900^{\circ} \mathrm{C}$.

The modified SEP samples, SEP-1000 and SEP-EF40, decompose with twostep weight loss instead of four-step, compared with pristine SEP. The first weight losses at the temperatures between $30^{\circ} \mathrm{C}-120^{\circ} \mathrm{C}$ for SEP- 1000 and $30^{\circ} \mathrm{C}$ $100^{\circ} \mathrm{C}$ for SEP-EF40 can be ascribed to the elimination of adsorbed water molecules on the surfaces. The second weight losses of the modified SEP samples at the temperature between $300^{\circ} \mathrm{C}-700^{\circ} \mathrm{C}$ are attributed to thermal degradation of

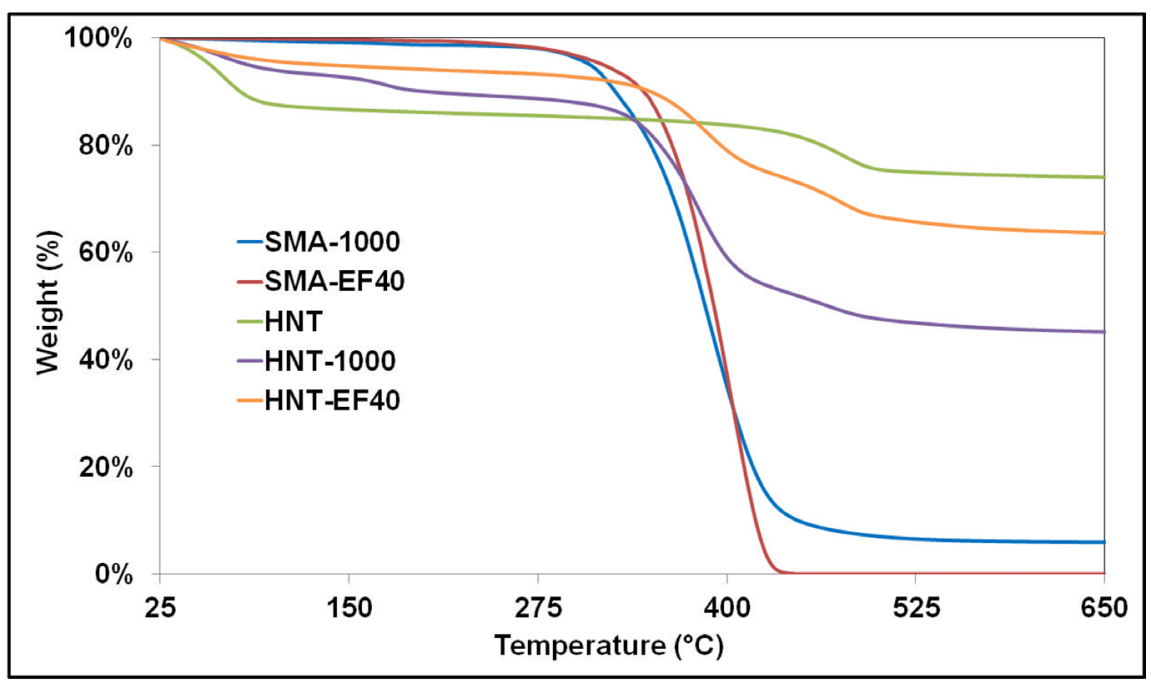

Figure 5. Thermal analysis results of HNT, commercial SMAs and modified HNT samples.



Figure 6. Thermal analysis results of SEP, commercial SMAs and modified SEP samples. 
SMA copolymers grafted onto the SEP surface. The char residue values of SEP-1000 and SEP-EF40 at $900^{\circ} \mathrm{C}$ are 43 and $58 \mathrm{wt}$ \%, respectively. According to char residue values, it can be said that SMA-1000 and SMA-EF copolymers could be grafted on the surface at 43 and $15 \mathrm{wt}$. \%, respectively. This result shows that SMA-1000 is also grafted to SEP surfaces at higher efficiency than SMA-EF40, as well as grafted to HNT surfaces.

\subsection{Morphological Properties of the Modified Nanoclays}

FESEM images of the pristine HNT and modified HNT with SMA-1000 (HNT1000) are presented in Figure 7(a) and Figure 7(b), respectively. Typical cylindrical and some irregular shapes of HNT nanotubes with varying lengths in individual form can be seen in Figure 7(a). After the surface modification, the



Figure 7. FESEM images of (a) Pristine HNT; (b) HNT-1000; (c) Pristine SEP; (d) SEP-1000. 
agglomeration occurred within the modified nanotubes and the singular form of the tubes disappeared (Figure 7(b)) due to organic structures on the surfaces.

Figure $7(\mathrm{c})$ and Figure $7(\mathrm{~d})$ give the FESEM micrographs of pristine SEP and modified SEP with SMA-1000 (SEP-1000), respectively. The pristine SEP seems uniform and smooth surfaces at low magnification image. However, the modification caused to needle type aggregates on the surfaces and hence the smoothness of the SEP surfaces reduced due to organic molecules assembly (Figure $7(d))$.

\section{Conclusion}

In this study, halloysite and sepiolite were modified with styrene-maleic anhydride copolymers via chemical method. The modified nanoclays were characterized by FTIR spectroscopy, X-ray diffraction, thermal gravimetric analysis, and scanning electron microscopy. The characterization results showed that SMA copolymers were grafted onto the nanoclays surfaces at different grafting ratios depending on their molecular weight and styrene/maleic anhydride molar ratios. The differences of the nanoclays also affected the grafting ratios. It can be concluded that SMA-1000, having lower molecular weight and higher maleic anhydride content than those of SMA-EF40, displays higher efficiency to graft onto both nanoclays surfaces.

\section{Acknowledgements}

The authors would like to thank Cray Valley for supplying the SMA copolymers, to Eczacıbaşı ESAN for providing the halloysite nanotubes.

\section{References}

[1] Alexandre, M. and Dubois, P. (2000) Polymer-Layered Silicate Nanocomposites: Preparation, Properties and Uses of A New Class of Materials. Materials Science and Engineering, 28, 1-63. https://doi.org/10.1016/s0927-796x(00)00012-7

[2] Calabi-Floody, M., Theng, B.K.G., Reyes, P. and Mora, M.L. (2009) Natural Nanoclays: Applications and Future Trends: A Chilean Perspective. Clay Minerals, 44, 161-176. https://doi.org/10.1180/claymin.2009.044.2.161

[3] Kiliaris, P., Papaspyrides, C.D. and Pfaendner, R. (2009) Influence of Accelerated Aging on Clay-Reinforced Polyamide 6. Polymer Degradation and Stability, 94, 389-396. https://doi.org/10.1016/j.polymdegradstab.2008.11.016

[4] Ray, S.S. and Okamoto, M. (2003) Polymer/Layered Silicate Nanocomposites: A Review Form Preparation to Processing. Progress in Polymer Science, 28, 1539-1641. https://doi.org/10.1016/j.progpolymsci.2003.08.002

[5] Wang, Z., Massam, J. and Pinnavaia, T.J. (2000) Epoxy-Clay Nanocomposites. In: Pinnavaia, T.J. and Beal, G.W., Eds., Polymer-Clay Nanocomposites, John Wiley \& Sons, Chichester, 127-149.

[6] Zeng, Q.H., Yu, A.B., Lu, G.Q. and Paul, D.R. (2005) Clay-Based Polymer Nanocomposites: Research and Commercial Development. Journal of Nanoscience and Nanotechnology, 5, 1574-1592. https://doi.org/10.1166/jnn.2005.411

[7] Leszczynska, A., Njuguna, J., Pielichowski, K. and Banerjee, J.R. (2007) Polymer/Montmorillonite Nanocomposites with Improved Thermal Properties Part I. 
Factors Influencing Thermal Stability and Mechanisms of Thermal Stability Improvement. Thermochimica Acta, 453, 75-96.

[8] Anadão, P., Sato, L.F., Wiebeck, H. and Valenzuela-Díaz, F.R. (2010) Montmorillonite as a Component of Polysulfone Nanocomposite Membranes. Applied Clay Science, 48, 127-132. https://doi.org/10.1016/j.clay.2009.12.011

[9] Zhang, Y., Liu, Q., Zhang, S., Zhang, Y., Zhang, Y. and Liang, P. (2016) Characterization of Kaolinite/Styrene Butadiene Rubber Composite: Mechanical Properties and Thermal Stability. Applied Clay Science, 124-125, 167-174. https://doi.org/10.1016/j.clay.2016.02.002

[10] Zhang, Y., Liu, Q., Xiang, J. and Frost, R.L. (2014) Thermal Stability and Decomposition Kinetics of Styrene-Butadiene Rubber Nanocomposites Filled with Different Particle Sized Kaolinites. Applied Clay Science, 95, 159-166.

https://doi.org/10.1016/j.clay.2014.04.002

[11] Zheng, S., Wang, T., Liu, D., Liu, X., Wang, C. and Tong, Z. (2013) Fast Deswelling and Highly Extensible Poly (N-isopropylacrylamide)-Hectorite Clay Nanocomposite Cryogels Prepared by Freezing Polymerization. Polymer, 54, 1846-1852.

https://doi.org/10.1016/j.polymer.2013.02.008

[12] Velasco, J.I., Antunes, M., Ayyad, O., Lopez-Cuesta, J.M., Gaudon, P., Saiz-Arroyo, C., Rodriguez-Perez, M.A. and de Saja, J.A. (2007) Foaming Behaviour and Cellular Structure of LDPE/Hectorite Nanocomposites. Polymer, 48, 2098-2108. https://doi.org/10.1016/j.polymer.2007.02.008

[13] Zhen, W., Lu, C., Li, C. and Liang, M. (2012) Structure and Properties of Thermoplastic Saponite/Poly (Vinyl Alcohol) Nanocomposites. Applied Clay Science, 57, 6470. https://doi.org/10.1016/j.clay.2012.01.002

[14] Wang, W., Zhen, W., Bian, S. and Xi, X. (2015) Structure and Properties of Quaternary Fulvic Acid-Intercalated Saponite/Poly (Lactic Acid) Nanocomposites. Applied Clay Science, 109-110, 136-142. https://doi.org/10.1016/j.clay.2015.02.033

[15] Liu, M., Jia, Z., Jia, D. and Zhou, C. (2014) Recent Advanced in Research of Halloyiste Nanotubes-Polymer Nanocomposites. Progress in Polymer Science, 39, 1498-1525. https://doi.org/10.1016/j.progpolymsci.2014.04.004

[16] Liu, M., Zhang, Y. and Zhou, C. (2013) Nanocomposites of Halloyiste and Polylactide. Applied Clay Science, 75-76, 52-59. https://doi.org/10.1016/j.clay.2013.02.019

[17] Daitx, T.S., Carli, L.N., Crespo, J.S. and Mauler, R.S. (2015) Effects of the Organic Modification of Different Clay Minerals and Their Application in Biodegradable Polymer Nanocomposites of PHBV. Applied Clay Science, 115, 157-164. https://doi.org/10.1016/j.clay.2015.07.038

[18] Yuan, P., Southon, P.D., Liu, Z., Green, M.E.R., Hook, J.M., Antill, S.J. and Kepert, C.J. (2008) Functionalization of Halloysite Clay Nanotubes by Grafting with $\gamma$-aminopropyltriethoxysilane. Journal of Physical Chemistry C, 112, 15742-15751. https://doi.org/10.1021/jp805657t

[19] Pasbakhsh, P., Ismail, H., Fauzi, M.N.A. and Bakar, A.A. (2010) EPDM/Modified Halloysite Nanocomposite. Applied Clay Science, 48, 405-413.

https://doi.org/10.1016/j.clay.2010.01.015

[20] Lecouvet, B., Gutierrez, J.G., Sclavons, M. and Bailly, C. (2011) Structure-Property Relationships in Polyamide 12/Halloysite Nanotube Nanocomposites. Polymer Degradation and Stability, 96, 226-235. https://doi.org/10.1016/j.polymdegradstab.2010.11.006

[21] Guo, B., Zou, Q., Lei, Y. and Jia, D. (2009) Structure and Performance of Polyamide 6/Halloysite Nanotubes Nanocomposites. Polymer Journal, 41, 835-842. 
https://doi.org/10.1295/polymj.PJ2009110

[22] Basurta, F.C., Garcia-Lopez, D., Villarreal-Bastardo, N., Merino, J.C. and Pastor, J.M. (2013) Composites and Nanocomposites of ABS: Synergy between Glass Fiber and Nano-Sepiolite. Composites Part B, 47, 42-47. https://doi.org/10.1016/j.compositesb.2012.08.026

[23] Moazeni, N., Mohamad, Z. and Dehbari, N. (2015) Study of Silane Treatment on Poly-Lactic Acid(PLA)/Sepiolite Nanocomposite Thin Films. Journal of Applied Polymer Science, 132, 41428. https://doi.org/10.1002/app.41428

[24] Can, M.F., Avdan, L. and Bedeloglu, A.C. (2015) Properties of Biodegradable PVA/ Sepiolite-Based Nanocomposite Fiber Mats. Polymer Composites, 36, 2334-2342. https://doi.org/10.1002/pc.23147

[25] Bhagabati, P., Chaki, T.K. and Khastgir, D. (2015) Chlorinated Polyethylene (CPE)/ Ethylene Metacrylate Copolymer (EMA)/Sepiolite Nanocomposite via a Facile OneStep Covalent Modification Technique. Royal Society of Chemistry Advances, 5, 60294-60306.

[26] Sun, A., d'Espinose de la Caillerie, J.B. and Fripiat, J.J. (1995) A New Microporous Material: Aluminated Sepiolite. Microporous Materials, 5, 135-142.

[27] Murray, H.H. (2000) Traditional and New Applications for Kaolin, Smectite, and Palygorskite: A General Overview. Applied Clay Science, 17, 207-306. https://doi.org/10.1016/S0169-1317(00)00016-8

[28] Sham, M.L., Li, J., Ma, P.C. and Kim, J.K. (2009) Cleaning and Functionalization of Polymer Surfaces and Nanoscale Carbon Fillers by UV/Ozone Treatment: A Review. Journal of Composite Materials, 43, 1537-1564. https://doi.org/10.1177/0021998308337740

[29] Baseghi, S., Garmabi, H., Gavgani, J.N. and Adelnia, H. (2015) Lightweight HighDensity Polyethylene/Carbonaceous Nanosheets Microcellular Foams with Improved Electrical Conductivity and Mechanical Properties. Journal of Materials Science, 50, 4994. https://doi.org/10.1007/s10853-015-9048-3

[30] Mallakpour, S. and Sirous, F. (2015) Surface Coating of $\alpha-\mathrm{Al}_{2} \mathrm{O}_{3} \mathrm{Nanoparticles}$ with Poly(vinyl alcohol) as Biocompatible Coupling Agent for Improving Properties of Bio-Active Poly(amide-imide) Based Nanocomposites Having L-Phenylalanine Linkages. Progress in Organic Coatings, 85, 138. https://doi.org/10.1016/j.porgcoat.2015.03.021

[31] Joo, Y., Jeon, Y., Lee, S.U., Sim, J.H., Ryu, J., Lee, S., Lee, H. and Sohn, D. (2012) Aggregation and Stabilization of Carboxylic Acid Functionalized Halloysite Nanotubes. Journal of Physical Chemistry C, 116, 18230-18235. https://doi.org/10.1021/jp3038945

[32] Du, M., Guo, B., Liu, M. and Jia, D. (2006) Preparation and Characterization of Polypropylene Grafted Halloysite and Their Compatibility Effect to Polypropylene/ Halloysite Composite. Polymer Journal, 38, 1198-1204. https://doi.org/10.1295/polymj.PJ2006038

[33] Garcia, N., Guzman, J., Benito, E., Esteban-Cubillo, A., Aguilar, E., Santaren, J. and Tiemblo, P. (2011) Surface Modification of Sepiolitein Aqueous Gels by Using Methoxy Silanes and Its Impact on the Nanofiber Dispersion Ability. Langmuir, 27, 3952-3959. https://doi.org/10.1021/la104410r

[34] Garcia-Lopez, D., Fernandez, J.F., Merino, J.C., Santaren, J. and Pastor, J.M. (2010) Effect of Organic Modification of Sepiolite for PA 6 Polymer/Organoclay Nanocomposites. Composites Science and Technology, 70, 1429-1436.

https://doi.org/10.1016/j.compscitech.2010.05.020 
[35] Jia, D., Lin, J.-Q., Yao, X.-F. and Wang, Y.-L. (2004) Modification of Sepiolite by Treatment with Methyl Triethoxysilane. Journal of Wuhan University of Technology-Materials Science Edition, 19, 44-47. https://doi.org/10.1007/BF02838361

[36] Wang, H., Shi, H., Qi, M., Zhang, L., Zhang, X. and Qi, L. (2013) Structure and Thermal Performance of Poly(styrene-co-maleic anhydride)-g-Alkyl Alcohol Comb-Like Copolymeric Phase Change Materials. Thermochimica Acta, 564, 34 38. https://doi.org/10.1016/j.tca.2013.04.025

[37] Rajput, R.S., Rupainwar, D.C. and Singh, A. (2009) A Study on Styrene Maleic Anhydride Modification by Benzoic Acid Derivatives and Dimethyl Sulfoxide. International Journal of Chem Tech Research, 1, 915-919.

[38] Wan, C. and Chen, B. (2011) Synthesis and Characterization of Biomimetic Hydroxyapatite/Sepiolite Nanocomposites. Nanoscale, 3, 693-700. https://doi.org/10.1039/C0NR00650E

[39] Frost, R.L., Locos, O.B., Ruan, H. and Kloprogge, J.T. (2001) Near-Infrared and Mid-Infrared Spectroscopic Study of Sepiolites and Palygorskites. Vibrational Spectroscopy, 27, 1-13. https://doi.org/10.1016/S0924-2031(01)00110-2

[40] Bidsorkhi, H.C., Soheilmoghaddam, M., Pour, R.H., Adelnia, H. and Mohamad, Z. (2014) Mechanical, Thermal and Flammability Properties of Ethylene-Vinyl Acetate (EVA)/Sepiolite Nanocomposites. Polymer Testing, 37, 117-122. https://doi.org/10.1016/j.polymertesting.2014.05.007

[41] Bischoff, E., Daitx, T., Simon, D.A., Schrekker, H.S., Liberman, S.A. and Mauler, R.S. (2015) Organosilane-Functionalized Halloysite for High Performance Halloysite/Heterophasic Ethylene-Propylene Copolymer Nanocomposites. Applied Clay Science, 112-113, 68-74. https://doi.org/10.1016/j.clay.2015.04.020

[42] Barrientos-Ramírez, S., Oca-Ramírez, G.M.D., Ramos-Fernández, E.V., SepúlvedaEscribano, A., Pastor-Blas, M.M. and González-Montiel, A. (2011) Surface Modification of Natural Halloysite Clay Nanotubes with Aminosilane. Application as Catalyst Supports in the Atom Transfer Radical Polymerization of Methyl Metharylate. Applied Catalysis A, 406, 22-33. https://doi.org/10.1016/j.apcata.2011.08.003

[43] Carli, L.N., Daitx, T.S., Soares, G.V., Crespo, J.S. and Maule,r R.S. (2014) The Effects of Silane Coupling Agents on The Properties of PHBV/Halloysite Nanocomposites. Applied Clay Science, 87, 311-319. https://doi.org/10.1016/j.clay.2013.11.032

[44] Chen, H., Lu, H., Zhou, Y., Zheng, M., Ke, C. and Zeng, D. (2012) Study on Thermal Properties of Polyurethane Nanocomposites Based on Organosepiolite. Polymer Degradation and Stability, 97, 242-247. https://doi.org/10.1016/j.polymdegradstab.2011.12.025 
Submit or recommend next manuscript to SCIRP and we will provide best service for you:

Accepting pre-submission inquiries through Email, Facebook, LinkedIn, Twitter, etc. A wide selection of journals (inclusive of 9 subjects, more than 200 journals)

Providing 24-hour high-quality service

User-friendly online submission system

Fair and swift peer-review system

Efficient typesetting and proofreading procedure

Display of the result of downloads and visits, as well as the number of cited articles Maximum dissemination of your research work

Submit your manuscript at: http://papersubmission.scirp.org/

Or contact nr@scirp.org 